\title{
Streptococcus Mutans and Lactobacillus Species Infection in Obese and Non- Obese School Children in Accra, Ghana
}

\section{Ndanu TA $^{* 1}$, Aryeetey $\mathrm{R}^{2}$, Sackeyfio $\mathrm{J}^{1}$, Otoo $\mathrm{G}^{3}$, Lartey $\mathrm{A}^{3}$, Opintan $\mathrm{JA}^{4}$ and Agyeman $\mathrm{PN}^{4}$}

${ }^{1}$ School of Medicine and Dentistry, College of Health Sciences, University of Ghana, Legon

${ }^{2}$ School of Public Health, College of Health Sciences, University of Ghana, Legon

${ }^{3}$ Department of Nutrition and Food Sciences, University of Ghana, Legon

${ }^{4}$ Department of Microbiology, School of Medicine and Dentistry, College of health Sciences, UG, Legon

${ }^{*}$ Corresponding author: Ndanu TA, School of Medicine and Dentistry, College of Health Sciences, University of Ghana, Legon, E-mail: tomandanu@chs.edu.gh

Citation: Ndanu TA, Aryeetey R, Sackeyfio J, Otoo G, Lartey A, et al. (2015) Streptococcus Mutans and Lactobacillus Species Infection in Obese and Non-Obese School Children in Accra, Ghana. J Obes Overweig 1(1): 101. doi: 10.15744/2455-7633.1.101

Received Date: November 25, 2014 Accepted Date: May 19, 2015 Published Date: May 26, 2015

\begin{abstract}
Background: Streptococcus mutans and Lactobacillus species are major bacteria associated with dental caries. In the presence of fermentable sugars and poor oral hygiene these bacteria increase risk of caries. Some studies have associated obesity with dental caries while others did not. High sugar snacks are risks for both obesity and dental caries.

Objectives: This study aimed at determining Streptococcus mutans and Lactobacillus species infection and its relationship with dental caries among obese and non-obese children.

Methods: Oral plaque was taken from 75 each of obese and non-obese children from private schools in Accra, Ghana. The plaque was pre-enriched in thioglycollate broth for 48 hours at $37^{\circ} \mathrm{C}$. Streptococcus mutans and Lactobacillus species were recovered after sub-culturing the broths onto Mitis Salivarius Bacitracin (MSB) and Man Rogosa Sharpe (MRS) selective plates, respectively, and incubation at $37^{\circ} \mathrm{C}$ under anaerobic conditions. Bacteria isolates on the selective plates were identified using Gram morphology and catalase activity.

Results: Streptococcus mutans was isolated in 51 (33.6\%) of all 150 children. The prevalence of Streptococcus mutans was significantly higher in the obese children 31 (41.3\%) than the non-obese 20 (26.0\%), $\mathrm{p}=0.033$. Recovery of Lactobacillus species was low 2 (1.3\%). Caries prevalence was similar in the obese $14.9 \%$ and non-obese $15.1 \%$. There was no significant association between Streptococcus mutans infection and the dental caries. Overall Silness and LÖe Plaque Index of $1.1 \pm 0.5$ indicate good oral hygiene status for the children.

Conclusion: Obese school children had higher oral Streptococcus mutans infections than non-obese children but this was not significantly associated with dental caries prevalence.
\end{abstract}

Keywords: Streptococcus mutans; Lactobacillus species; Obese children; Dental caries; Accra

\section{Introduction}

Several bacteria colonize the oral cavity. Some are involved in oral diseases including dental caries. Dental caries is one of the commonest oral problems in children [1]. Acid producing oral bacteria such as Streptococcus mutans and Lactobacillus species are the major bacteria associated with caries [2]. For a long time it was thought that the presence of these bacteria alone may lead to dental caries but later studies have demonstrated that there were cases where caries occurred even in the absence of these bacteria [3,4]. Some of these other bacteria include Streptococcus sanguinis, Streptococcus oralis, Neisseria subflava. However, when Streptococcus mutans and Lactobacillus species dominate the plaque caries occurs faster [2,3]. Colonization by some of the oral bacterial starts even before the eruption of teeth in the mouth of children [5]. These bacteria are thought to be transmitted from mother to child [6-9].

Streptococcus mutans is an important bacterium for dental caries because it can colonize the tooth surfaces easily. It efficiently achieves this by synthesizing insoluble polysaccharides from simple sugars such as sucrose that allows it to adhere to the smooth surfaces. It is then able to ferment simple sugars into lactic acid reducing the plaque $\mathrm{pH}$ [10].

The association between obesity and caries in children has been reported. Studies in countries such as Sweden [11], Germany [12], Brazil [13], Mexico [14], India [15], and Thailand [16] all showed significant association between overweight/obesity with caries among obese children. On the other hand, studies from USA [17,18], France [19], Brazil [20], and Iran [21], did not find any significant association between obesity and caries experience among the children. A systematic review carried out on published articles from 1980 to 2012 showed that the relationship is still inconclusive [22]. 
It is known that oral hygiene practice, snacking habit and saliva flow affect the presence of caries-causing bacteria. The severity of dental caries therefore depends on the interplay of these factors [9]. High bacterial infection gives an indication of poorer oral hygiene status. Establishing significantly higher prevalence of bacterial infection among the obese would give an indication of possible increased caries risk. This study sought to demonstrate whether the child obesity is a major risk factor for caries or other important factors may play greater role in the child obesity and caries risk association.

Much data exist on oral bacteria in adults in many populations but there is very little information on the oral bacteria in obese children in Ghana. While significant association exist between child obesity and caries in some populations the situation between Ghanaian obese children is not known. This study therefore compared the prevalence of Streptococcus mutans in obese and nonobese school children and assessed its association with dental caries to determine how colonization or infection influences caries level in obese and non-obese children.

\section{Materials and Methods}

A cross-section of school children consisting of 75 obese and 75 non-obese children aged 9-15 years had their oral plaque samples collected and cultured for Streptococcus mutans and Lactobacillus species. Caries experience in the children was also investigated by two calibrated dental surgeons, kappa value of 0.96 . These school children were selected from a sample of 547 children chosen from 8 private schools in Accra, which was part of a larger study. Out of those who had visible plaque on their teeth, the sample for this study was randomly selected by a ballot. Qualified dentists using dental curette took plaque samples, which were directly inoculated into thioglycollate broth by a microbiologist. These were sent to the Microbiology Department, University of Ghana School of Medical and Dentistry, for further processing.

The thioglycollate inoculum was incubated for 48 hours at $37^{\circ} \mathrm{C}$. Streptococcus mutans and Lactobacillus species were recovered after sub-culturing the broths onto Mitis Salivanus Bacitracin (MSB) and Man Rogosa Sharpe (MRS) selective agar plates respectively, using anaerobic GasPak at $37^{\circ} \mathrm{C}$ [23]. Media were purchased from Sigma-Aldrich, and Streptococcus mutans strain (ATCC 25175) kept at the Microbiology Department, was used in quality controls. The isolates were identified using Gram morphology and catalase activity [24,25]. The protocols for the study was reviewed and approved by the Ethical Review Board of the Noguchi Memorial Institute for Medical Research, University of Ghana [Reference: FWA 00001824, IRB 00001276, NMIMR-IRB CPN 054/09-10; IORG 0000908].

Data was captured and analyzed using SPSS version 20. Continuous data was summarized by means and standard deviation, and categorical variables were summarized by frequencies and percentage with $95 \%$ confidence intervals. T-test was used to compare the means and Chi-square used to compare the proportion within categories. Significant level was set at alpha $=0.05$. Results are presented as table and charts.

\section{Results}

Mean age of school children was $11.5 \pm 1.7$ years ranging from 9-15 years from primary classes 4 to Junior High School (JHS3). There was no significant difference in the mean age between the obese $(11.5 \pm 1.5$ years $)$ and the non-obese ( $11.6 \pm 1.7$ years), $\mathrm{p}=0.104$. Male female ratio was 1:1.3. Overall prevalence of Streptococcus mutans infection in the school children was $33.6 \%$.

Figure 1 shows the prevalence of Streptococcus mutans observed between obese and non-obese school children. There was significantly higher prevalence of Streptococcus mutans among the obese children 31 (41.3\%; 95\% CI, 30.6 - 52.7\%) compared to the non-obese 20 (26.0\%; 95\% CI1 7.6 - 37.5), p=0.033. Recovery of Lactobacillus species was very low 2 (1.3\%; 95\% CI, 0.4-8.5) in both study groups. Overall oral hygiene status as estimated by mean Silness and LÖe Plaque Index was $1.14 \pm 0.5$ and is considered good for most of the children. Among the obese the mean plaque score was $1.38 \pm 0.34$ and for the non-obese it was $1.4 \pm 0.4$. This gives an indication of acceptable oral hygiene status.

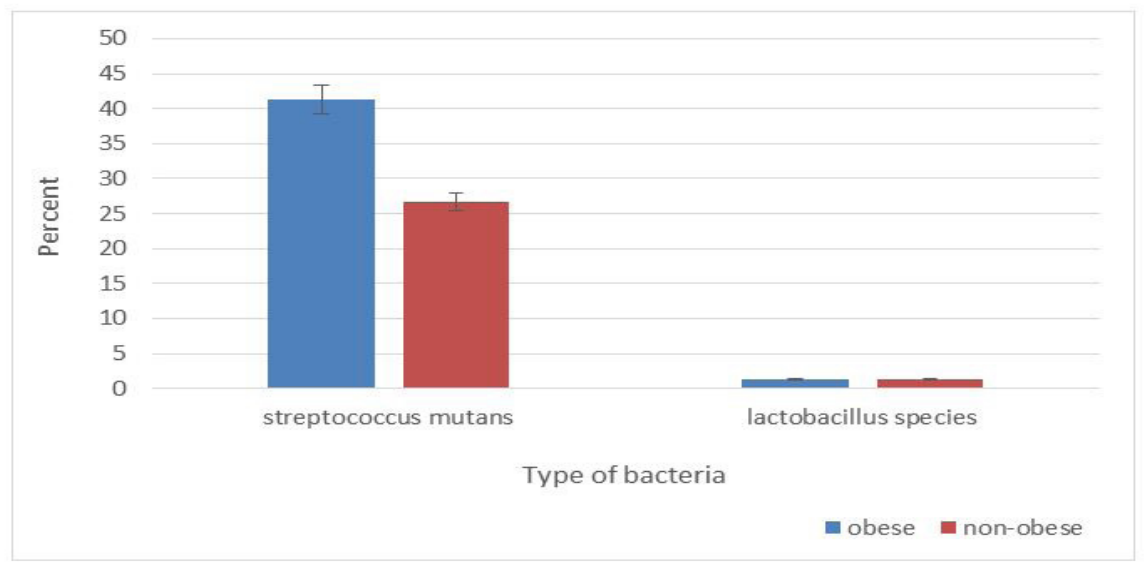

Figure 1: Prevalence of the Streptoccocus mutans and Lactobaccillus species in obese and non-obese school children, $\mathrm{P}=0.033$ 


\section{Caries prevalence and other oral conditions}

The overall caries prevalence in the population from which the sample for culture was taken is shown in Figure 2. Similar caries prevalence was observed between the obese and the non-obese children. Caries prevalence at age 12 years (recommended age by WHO for estimating childhood caries prevalence) showed marked but non-significant difference between obese and the nonobese school children.

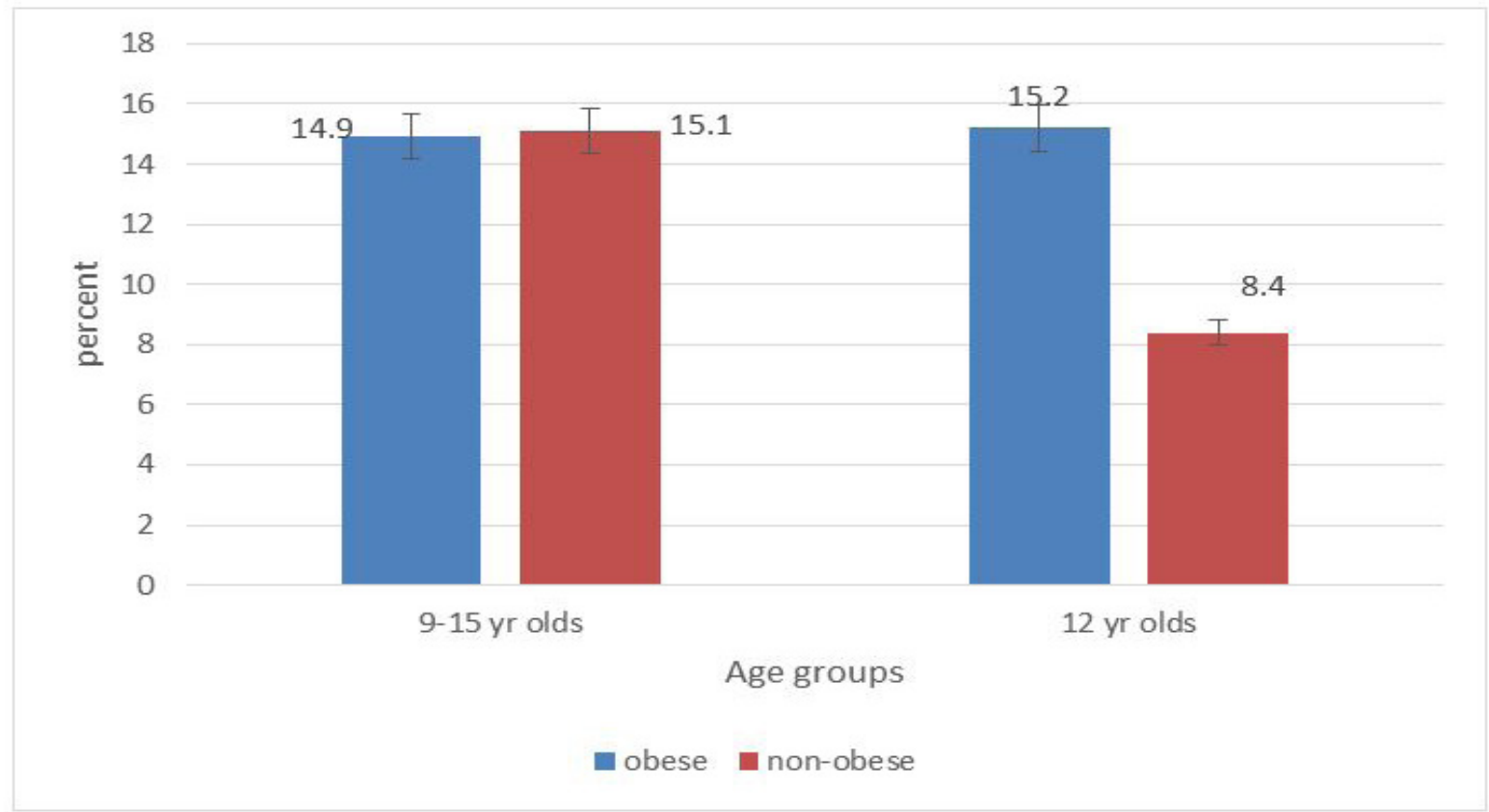

Figure 2: Caries prevalence in obese and non-obese entire population and the 12 year olds (WHO reference age for caries prevalence in children - WHO, 2009)

Comparison of Streptococcus mutans infection in carious and caries-free school children among the obese and non-obese groups is shown in Table 1. Similar prevalence was observed in carious and caries-free children in the obese group. No positive culture was observed for Streptococcus mutans in the non-obese children with caries but $27 \%$ of the non-obese children without caries had Streptococcus mutan infection. In both cases the differences were not significant.

\begin{tabular}{|l|l|c|c|c|}
\hline \multicolumn{5}{|c|}{ Streptococcus mutans culture } \\
\hline Obesity status & Caries experience & Positive & Negative & Total \\
\hline \multirow{5}{*}{ Obese } & Caries-absent & $27(41.5)$ & $38(58.5)$ & $65(100)$ \\
\cline { 2 - 5 } & caries present & $4(40.0)$ & $6(60.0)$ & $10(100)$ \\
\cline { 2 - 5 } & Total & $31(41.3)$ & $44(58.7)$ & $75(100)$ \\
\cline { 2 - 5 } & P-value $=$ & & 0.653 & \\
\hline Non-obese & Caries-absent & $20(27.4)$ & $51(72.6)$ & $71(100)$ \\
\hline & caries present & 0 & $4(100)$ & $4(100)$ \\
\hline & Total & $20(26.0)$ & $57(74.0)$ & $75(100)$ \\
\hline & P-value $=$ & & 0.151 & \\
\hline & & & & \\
\hline
\end{tabular}

\section{Discussion}

Table 1: Caries and Streptococcus mutans infections in obese and non-obese

The overall prevalence of Streptococcus mutans in the studied population was $33.6 \%$. In Italian children 6-11 year olds, a lower prevalence rate of $17.4 \%$ was reported using similar methods [26]. However, in a Brazilian study using polymerase chain reaction (PCR) amplification method, a higher prevalence of $85.7 \%$ was observed [27]. In our study the significantly higher prevalence in the obese $(41.3 \%)$ as against non-obese $(26.0 \%)$ was not expected since there was similar oral hygiene habits and dietary practices among the two groups.

The overall dental caries of $15.1 \%$ was relatively low in the population studied as compared to other studies where caries prevalence ranged between $35.5 \%$ in Nigeria [28] and $48.6 \%$ in Mexico [29]. The prevalence observed in our study was similar for the obese $(14.9 \%)$ and the non-obese (15.1\%). This may result from similar oral hygiene status as shown by similar plaque scores; obese 1.4 \pm 0.3 and $1.4 \pm 0.4$ for non-obese. In the current study, caries prevalence in the 12 year olds was nearly twice in the obese as that of the non-obese, though not significant. However, this prevalence is still lower, compared to a study in Nepal which reported a prevalence of $41 \%$ in $12-13$ year olds [30]. 
There was no association between the positive culture of Streptococcus mutans and dental caries either in the obese and the nonobese groups. Although there was higher infection in the obese that had caries than the carious non-obese children these differences was not significant. This result affirms the fact that the presence of the Streptococcus mutans alone does not indicate caries occurrence in the mouth. It requires other conditions to be met for the caries process to be initiated and sustained. This implies that interventions and preventive measures should emphasize appropriate dietary advice and oral hygiene instructions. These two measures should be able to keep the risk of caries very low even in the presence of the oral bacteria.

\section{Conclusion}

Higher Streptococcus mutans colonization was significantly associated with obesity in children. Lactobacillus colonization was very low among both the obese and non-obese children. The significantly higher levels of Streptococcus mutans in the obese children did not result in significant increase in caries among the obese. This might account for low caries in the population studied. This finding should inform treatment and prevention in terms of giving accurate dietary and oral hygiene counseling to patients with serious caries conditions.

\section{Acknowledgement}

We wish to express our gratitude to International Development Research Centre, (IDRC) - Canada for funding the study. We also wish to acknowledge the support and contribution of Dr. Indra Wadwani, Dr. Ivan Obed, and Dr. Albert Hammond for the collection of plaque samples. We thank University of Ghana School of Medicine and Dentistry (UGSMD), Dental programme for the use of their clinical tools and equipment for the fieldwork and lastly Microbiology Department of UGSMD for the use of their laboratory. The various schools, the school children, teachers and parents are well acknowledged.

We wish to state that there is no conflict of interest declaration to be made as no corporate interest funded this study.

\section{References}

1. Banas JA (2004) Virulence properties of Streptococcus mutans. Front Biosci 1: 1267-77.

2. Bradshaw DJ, Marsh PD (1994) Effect of sugar alcohols on the composition and metabolism of a mixed culture of oral bacteria grown in a chemostat. Caries Res 28: 251-6.

3. Bradshaw DJ, Marsh PD, Hodgson RJ, Visser JM (2002) Effects of glucose and fluoride on competition and metabolism within in vitro dental bacterial communities and biofilms. Caries Res 36: 81-6.

4. Li Y, Ku CY, Xu J, Saxena D, Caufield PW (2005) Survey of oral microbial diversity using PCR-based denaturing gradient gel electrophoresis. J Dent Res84: 559-64. 5. Bockmann MR, Harris AV, Bennett CN, Odeh R, Hughes TE, et al. (2011) Timing of Colonization of Caries-Producing Bacteria: An Approach Based on Studying Monozygotic Twin Pairs. Int J Dent doi.org/10.1155/2011/571573.

6. Li Y and Caufield PW (1995) The fidelity of initial acquisition of mutans streptococci by infants from their mothers. J Dent Res 74: 681-5.

7. Caufield PW (1997) Dental caries- a transmissible and infectious disease revisited: a position paper. Pediatr Dent. 19: 491-8.

8. Caufield PW, Li Y, Dasanayake A (2005) Dental caries: an infectious and transmissible disease. Compend Contin Educ Dent 26: 10-6.

9. Berkowitz RJ (2006) Mutans streptococci: acquisition and transmission. Pediatr Dent 28(2): 106-9.

10. Holt JG, SneathPH, Kreig NR (1994) Bergey's Manual of Determinative Bacteriology ( $9^{\text {th }}$ edn) Lippincott Williams \& Wilkins Publishers, Baltimore, USA.

11. Alm A, Fåhraeus C, Wendt LK, Koch G, Andersson-Gäre B (2008) Body adiposity status in teenagers and snacking habits in early childhood in relation to approximal caries at 15 years of age. Int J Paediatr Dent 18: 189-96.

12. Willershausen B, Moschos D, Azrak B, Blettner M (2007) Correlation between oral health and body mass index (BMI) in 2071 primary school pupils. Eur J Med Res 12: 295-9.

13. Oliveira LB, Sheiham A, Bönecker M (2008) Exploring the association of dental caries with social factors and nutritional status in Brazilian preschool children. Eur J Oral Sci 116: 37-43.

14. Vázquez-Nava F, Vázquez-Rodríguez EM, Saldívar-González AH, Lin-Ochoa D, Martinez-Perales GM (2010) Association between obesity and dental caries in a group of preschool children in mexico. J Public Health Dent 70: 124-30.

15. Sharma A, Hegde AM (2009) Relationship between body mass index, caries experience and dietary preferences in children. J Clin Pediatr Dent 34: 49-52.

16. Narksawat K, Tonmukayakul U, Boonthum A (2009) Association between nutritional status and dental caries in permanent dentition among primary schoolchildren aged 12-14 years, Thailand. Southeast Asian J Trop Med Public Health 40: 338-44.

17. Macek MD, Mitola DJ (2006) Exploring the association between overweight and dental caries among US children. Pediatr Dent 28: 375-80.

18. Kopycka-Kedzierawski DT, Auinger P, Billings RJ, Weitzman M (2008) Caries status and overweight in 2 to 18 year-old us children: findings from national surveys. Community Dent Oral Epidemiol 36: 157-67.

19. Tramini P, Molinari N, Tentscher M, Demattei C, Schulte AG (2009) Association between caries experience and body mass index in 12-year-old French children. Caries Res 43: 468-73.

20. Granville-Garcia AF, de Menezes VA, de Lira PI, Ferreira JM, Leite-Cavalcanti A (2008) Obesity and dental caries among preschool children in Brazil. Rev Salud Publica 10: 788-95.

21. Sadeghi M, Alizadeh F (2007) Association between dental caries and body mass index-for-age among 6-11- year-old children in Isfahan in 2007. J Dent Res Dent Clin Dent Prospects 1: 119-24.

22. Hayden C, Bowler JO, Chambers S, Freeman R, Humphris G, et al. (2012) Obesity and dental caries in children: a systematic review and meta-analysis. Community Dent Oral Epidemiol 41: 289-308.

23. Gutiérrez de Annan S, Ruíz de Valladares RE, Benito de Cárdenas IL (1997) Mitis salivarius-bacitracin 10\% sacarose agar for oral streptococci and Streptococcus mutans counts. Acta Odontol Latinoam 10: 47-53. 
24. Wyder AB, Boss R, Naskova J, Kaufmann T, Steiner A, Graber HU (2011) Streptococcus spp. and related bacteria: their identification and their pathogenic potential for chronic mastitis - a molecular approach. Res Vet Sci 91: 349-57.

25. Raemy A, Meylan M, Casati S, Gaia V, Berchtold B, et al. (2013) Phenotypic and genotypic identification of streptococci and related bacteria isolated from bovine intramammary infections. Acta Vet Scand 18: doi: 10.1186/1751-0147-55-53.

26. Gasparini R, Pozzi T, Fonzi L, Rossolini GM, Mazzini M (1989) Prevalence of streptococcus mutans and dental decay in school children from Siena (Italy). Eur J Epidemiol 5: 189-92.

27. Franco e Franco TC, Amoroso P, Marin JM, de Avila FA (2007) Detection of streptococcus mutans andstreptococcus sobrinus in dental plaque samples from Brazilian preschool children by polymerase chain reaction. Braz Dent J 18: 329-33.

28. Okoye L, Ekwueme O (2011) Prevalence of Dental Caries in a Nigerian Rural Community: A Preliminary Local Survey. Ann Med Health Sci Res 1: $187-95$.

29. Pontigo-Loyola AP, Medina-Solis CE, Borges-Yañez SA, Patiño-Marín N, Islas-Márquez A, et al. (2007) Prevalence and severity of dental caries in adolescents aged 12 and 15 living in communities with various fluoride concentrations. J Public Health Dent 67: 8-13.

30. Dixit LP, Shakya A, Shrestha M, Shrestha A (2013) Dental caries prevalence, oral health knowledge and practice among indigenous Chepang school children of Nepal. BMC Oral Health 13: 20. 